
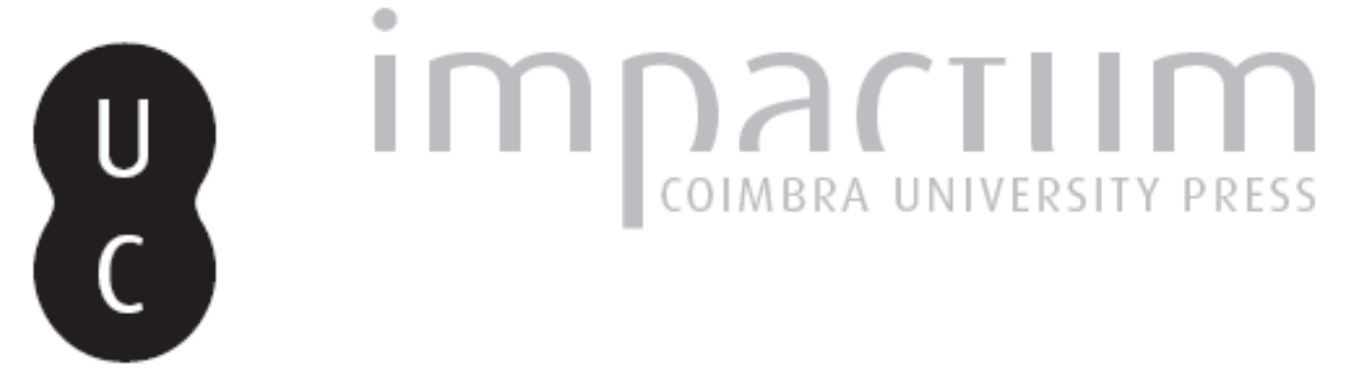

\title{
Mudanças climáticas: uma análise dos impactos sobre o meio ambiente e os direitos humanos
}

\author{
Autor(es): $\quad$ Avzaradel, Pedro Curvello Saavedra \\ Publicado por: Universidade Católica de Petrópolis \\ URL \\ persistente: \\ URI:http://hdl.handle.net/10316.2/33864 \\ DOI: \\ DOI:http://dx.doi.org/10.14195/2175-0947_2-1_5 \\ Accessed : $\quad$ 26-Apr-2023 12:14:14
}

A navegação consulta e descarregamento dos títulos inseridos nas Bibliotecas Digitais UC Digitalis, UC Pombalina e UC Impactum, pressupõem a aceitação plena e sem reservas dos Termos e Condições de Uso destas Bibliotecas Digitais, disponíveis em https://digitalis.uc.pt/pt-pt/termos.

Conforme exposto nos referidos Termos e Condições de Uso, o descarregamento de títulos de acesso restrito requer uma licença válida de autorização devendo o utilizador aceder ao(s) documento(s) a partir de um endereço de IP da instituição detentora da supramencionada licença.

Ao utilizador é apenas permitido o descarregamento para uso pessoal, pelo que o emprego do(s) título(s) descarregado(s) para outro fim, designadamente comercial, carece de autorização do respetivo autor ou editor da obra.

Na medida em que todas as obras da UC Digitalis se encontram protegidas pelo Código do Direito de Autor e Direitos Conexos e demais legislação aplicável, toda a cópia, parcial ou total, deste documento, nos casos em que é legalmente admitida, deverá conter ou fazer-se acompanhar por este aviso.

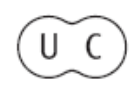



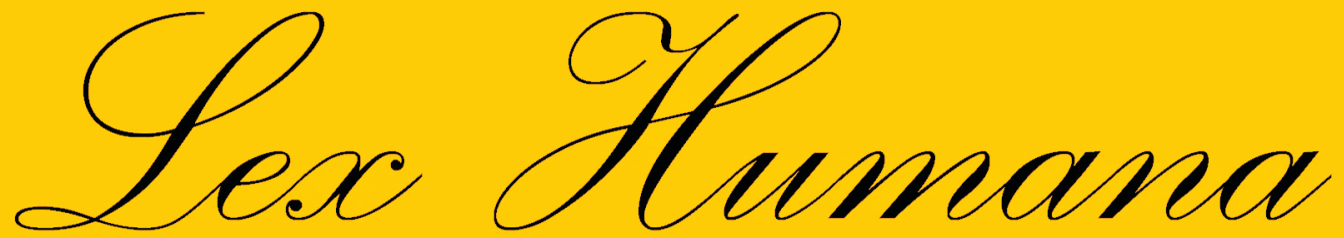

Revista do Programa de Pós-Graduação em Direito da UCP

ISSN(e) 2175-0947

Universidade Católica de Petrópolis Rua Benjamin Constant, 213 - Petrópolis - Centro CEP 25610-130

Tel: (24) 2244-4000 E-mail: lexhumana@ucp.br 


\title{
Mudanças Climáticas: \\ UMA ANÁLISE DOS IMPACTOS SOBRE O Meio Ambiente e os Direitos Humanos
}

\author{
Ms. Pedro Curvello Saavedra Avzaradel ${ }^{1}$
}

Resumo

O presente trabalho tem por objetivo apresentar os possíveis impactos decorrentes do fenômeno das mudanças climáticas sobre o meio ambiente e os direitos humanos a partir de estudos consagrados acerca do tema do ponto de vista das ciências naturais e sociais. Nesse sentido procura trazer à luz as conseqüências possíveis para o mundo contemporâneo e os esforços da comunidade internacional no sentido de enfrentar este problema. Será assim analisado o movimento atual de 'substituição' do Protocolo de Quioto, defendendo-se a necessidade de incorporação da discussão acerca dos impactos das mudanças climáticas sobre os direitos humanos de forma significativa.

Palavras-chave: Mudanças Climáticas - Direitos Humanos - Direito Ambiental Internacional

Abstract

This paper aims to present possible impacts aroused by

$\overline{1}$ Graduado em Direito pela UFRJ - Faculdade Nacional de Direito (2005). Mestre pelo PPGSD/ UFF - Programa de Pós-Graduação em Sociologia e Direito da Universidade Federal Fluminense. Atualmente é doutorando pela UERJ- Universidade do Estado do Rio de Janeiro. 
climate changes on the environment and the human rights, based upon well-known studies about this matter from the viewpoint (point of view) of both natural and social sciences. It seeks to highlight the possible consequences of climate change to the contemporary world and the international efforts to face this problem. It is also analyzed the efforts to substitute the Kyoto Protocol and the need to bring the debate about the impacts of climate changes to the human rights in a significant approach.

Key words: Climate Change - Human Rights - Environmental International Law

\section{Introdução}

O fenômeno das mudanças no clima não é consensual para a ciência² ${ }^{2}$ Não obstante, instâncias científicas que congregam grande quantidade de cientistas, organizações não-governamentais nacionais e internacionais afirmam que ele não apenas existe como já modifica o meio ambiente em todo o mundo.

Diretamente relacionado a tais mudanças, o chamado aquecimento global não é algo se possa chamar de inédito. Primeiramente, porque ele está ligado à intensificação de um

$2 \quad$ No Brasil, a corrente refratária à tese de que presenciamos mudanças climáticas provocadas pelo aquecimento global de origem antrópica é defendida, dentre outros e, especialmente, pelo cientista Luiz Carlos Molion. Para esse cientista, estamos numa fase cíclica de aquecimento que em breve dará lugar a um período de resfriamento. Par mais detalhes vide a entrevista concedida pelo cientista à revista IstoÉ em julho de 2007, na qual afirma que o aquecimento global é um terrorismo climático e que a

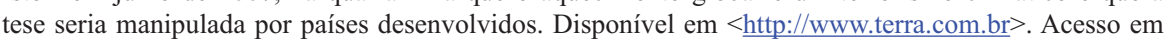
17/07/2007. No mesmo sentido Alberto Setzer, do Instituto Nacional de Pesquisas Espaciais (INPE), em entrevista ao Jornal O Globo (08/03/2007, Caderno Ciência, p. 50) disse ser cedo para afirmar que as mudanças climáticas são induzidas pelo homem e alega que existe uma tendência de resfriamento do planeta após 2005. Para ele, as mudanças climáticas somente podem ser observadas na Península Antártica, não havendo grandes alterações na parte interior do continente antártico. 
fenômeno existente há muitos milhões de anos, o efeito estufa.

Em segundo lugar, diversos são os registros de preocupações científicas relacionadas com o aumento da concentração dos chamados gases de efeito estufa (GEE) na atmosfera apontando um nexo causal entre tal aumento e o da temperatura media da terra em razão de atividades humanas. Michael Grubb, Christian Vrolijk e Duncan Brack trazem a seguinte observação:

“O Efeito Estufa não é uma preocupação nova. Em 1827, o cientista francês Fourier sugeriu que a atmosfera terrestre aquece a superfície, deixando passar a radiação solar de alta energia e armazenando parte das longas ondas de radiação que voltam da superfície. Isto é causado por uma série de 'gases de efeito estufa', notavelmente dióxido de carbono e vapor d'água. No final do século XIX, o cientista sueco Arrhemius postulou que o aumento do volume de dióxido de carbono, emitido pelas fábricas da Revolução Industrial estava mudando a composição da atmosfera, aumentando a proporção dos gases de efeito estufa, e que isso iria causar o aumento de temperatura da terra" ${ }^{3}$.

3 (The Kyoto Protocol: Guide And Assessment. Royal Institute of International Affairs, London, 1999, p.3). No original: The greenhouse effect is not a new concern. As early as 1827 , the French Cientist Fourier suggested that the earth's atmosphere warms the surface by letting through high-energy solar radiation but trapping part of the longer-wave heat radiation coming back from the surface. This is caused by a number of 'greenhouse gases', notably carbon dioxide and water vapour. At the end of nineteenth century the Swedish scientist Arrhemius postulated that the growing volume of carbon dioxide emitted by the factories of the Industrial Revolution was changing the composition of the atmosphere, increasing the proportion of greenhouse gases, and that would cause the earth's temperature to rise. 
Numa ligeira síntese, o aquecimento global é o gradual e acelerado incremento da temperatura média da superfície terrestre. Este fenômeno, por sua vez, tem por causa a intensificação do efeito estufa ${ }^{4}$. Mas qual seria o conceito de clima?

Oclima pode ser conceituado como a descrição estatística da variação de temperaturas e o seu significado através de medidas relevantes do sistema atmosférico-oceânico ao longo de períodos de tempo que variam de semanas a milhares ou milhões dos anos. A mudança do clima é definida como uma variação significativa no estado médio do clima ou em sua variação, persistindo por um período prolongado (tipicamente décadas ou mais longo). A mudança do clima afetará a ecologia do planeta impactando a biodiversidade, causando extinções de espécies, alterando padrões migratórios, e perturbando ecossistemas em maneiras incontáveis. As mudanças climáticas impactarão as sociedades humanas afetando a agricultura, as fontes de água e sua a qualidade, padrões do estabelecimento, e a saúde ${ }^{5}$.

$4 \quad$ Atlas One Planet, Many people, United Nations Environment Program, 2005, p.75. Disponível em $<$ http://www.na.unep.net $>$. Acesso em 22/06/2007.

$5 \quad$ Atlas One Planet, Many people, United Nations Environment Program, 2005, pg. 78 e79. Disponível em $<\underline{\text { http: } / / w w w . n a . u n e p . n e t ~}>$. Acesso em 07/07/2007. No original: "Climate is the statistical description in terms of the mean and variability of relevant measures of the atmosphere-ocean system over periods of time ranging from weeks to thousands or millions of years. Climate change is defined as a statistically significant variation in either the mean state of the climate or in its variability, persisting for an extended period (typically decades or longer)...Climate change will affect the ecology of the planet by impacting biodiversity, causing species extinctions, altering migratory patterns, and disturbing 
O efeito estufa do qual tanto se tem ouvido falar ultimamente consiste na retenção de calor pela atmosfera em razão da presença de determinados compostos gasosos em sua estrutura. Devemos salientar que o efeito estufa per si é um fenômeno natural, sempre existente e cuja natureza é irreversível.

Os chamados gases de efeito estufa $(\mathrm{GEE})^{6}$ podem ser concebidos como um cobertor, que, em condições normais, mantém a Terra a uma temperatura média que viabiliza a sobrevivência de seres e organismos vivos diversos. Estima-se que na ausência desses gases a Terra não reteria calor, tendo uma temperatura média mais baixa do que a atual entre $18^{\circ} \mathrm{C}$ e $30^{\circ} \mathrm{C}$.

Em síntese, o efeito estufa ocorre da seguinte maneira: i) os raios de sol ultrapassam os GEE; ii) ao incidirem sobre objetos diversos na terra, esses raios provocam calor que se propaga até encontrar os mesmos GEE; iii) esses gases, que permitem a passagem dos raios solares, bloqueiam o calor emitido pelo planeta. Esse calor provém do movimento de substancias, organismos e máquinas, da agitação de moléculas, aglomerados de substâncias químicas, das reações químicas, enfim, da vida na terra.

Os GEE possuem ciclos naturais de emissão, dispersão e absorção pelos ecossistemas terrestres e marinhos. Assim, por exemplo, erupções vulcânicas dispersam grande quantidade de GEE que são absorvidos pelo crescimento de plantas terrestres ou de organismos marinhos. A capacidade dos GEE reterem calor varia de acordo com

ecosystems in countless ways. Climate change will impact human societies by affecting agriculture, water supplies, water quality, settlement patterns, and health".

6 Os gases de efeito estufa considerados de origem antrópica e regulados pela Convenção Quadro sobre Mudanças Climáticas e pelo Protocolo de Quioto estão listados no Anexo A do último acordo. São eles: Dióxido de carbono (CO2); Metano (CH4); Óxido nitroso (N2O); Hidrofluorcarbonos (HFCs); Perfluorcarbonos (PFCs); Hexafluoreto de enxofre (SF6). 
sua composição química e com o tempo em que permanecem na atmosfera. O problema está no rápido aumento da espessura desse cobertor causado pelas emissões antrópicas de GEE, especialmente desde a Revolução Industrial. De acordo com as conclusões do IPCC:

“As concentrações atmosféricas globais de
dióxido de carbono, metano e óxido nitroso
aumentaram bastante em conseqüência
das atividades humanas desde 1750 e
agora ultrapassam em muito os valores
pré-industriais determinados com base em
testemunhos de gelo de milhares de anos ${ }^{7}$. Os
aumentos globais da concentração de dióxido
de carbono se devem principalmente ao uso
de combustíveis fósseis e à mudança no uso
da terra. Já os aumentos da concentração
de metano e óxido nitroso são devidos
principalmente à agricultura" ${ }^{8}$.

$7 \quad$ Acesso em 15/09/07). Os testemunhos de gelo são pedaços retirados de grandes e antigas geleiras e que, em sua composição, possuem moléculas de ar através das quais cientistas conseguem medir a as concentrações de GEE em determinada época. A expressão C02e se refere ao dióxido de carbono equivalente. Para facilitar a quantificação dos GEE, o Protocolo de Quioto (artigo $3^{\circ}$, inciso I) determinou que todos fossem expressos em C02e. A conversão dos valores se dá com base no potencial de retenção de calor dos outros GEE em comparação com o do C02.

$8 \quad$ Mudança do Clima 2007: A Base das Ciências Físicas Contribuição do Grupo de Trabalho I ao Quarto Relatório de Avaliação do Painel Intergovernamental sobre Mudança do Clima. Genebra, 2007, p.3. Versão traduzida para o português e disponível em www.mct.gov.br/clima. Segundo outro importante estudo, o Stern Review, Os estoques atuais dos gases com efeito de estufa na atmosfera são equivalentes a cerca de 430 partes por milhão (PPM) de $\mathrm{CO}_{2}$, em comparação com apenas 280 PPM antes da Revolução Industrial. Estas concentrações já provocaram um aquecimento global superior a meio grau Celsius e resultarão em pelo menos mais meio grau nas próximas décadas, devido à inércia do sistema climático. Mesmo se o fluxo de emissões não aumentasse, em 2050 a quantidade de GEE na atmosfera atingiria o dobro dos níveis pré-industriais - ou seja $550 \mathrm{PPM}$ de $\mathrm{CO}_{2} \mathrm{e}$ - e continuaria a crescer. Mas o fluxo anual das emissões está acelerando, à medida que as economias em rápido crescimento investem em infraestruturas intensivas em carbono e que a procura por energia e de transportes aumenta no mundo inteiro. O nível de 550 PPM de $\mathrm{CO}_{2}$ e poderá já ser atingido em 2035. A este nível, existe uma possibilidade de pelo menos $77 \%$ - e talvez de até $99 \%$, segundo o modelo climático utilizado - de um aumento superior 
O principal gás dentre com capacidade de armazenar calor e emitido por atividades antrópicas é o dióxido de carbono (CO2), em razão de estar associado a diversas práticas sociais, dentre as quais podemos destacar o uso de combustíveis fósseis?.

De um lado, o aparecimento de grandes centros urbanos em todo o mundo e a demanda massificada de produtos e serviços com intenso consumo energético tornou-se insustentável climaticamente por estarem todas essas práticas até hoje associadas à combustão de hidrocarbonetos, compostos formados de hidrogênio e carbono e cujo consumo importa na emissão de C02. De outro, podem ser citadas as práticas insustentáveis relacionadas com o uso da terra.

Por isso a concentração em que se encontra na atmosfera tem aumentado de maneira progressiva, significativa e preocupante sob o ponto de vista do equilíbrio climático ${ }^{10}$.

a $2^{\circ} \mathrm{C}$ da temperatura média global (Stern Review: the economics of climate change. Cambridge, 2006. Sumário Executivo traduzido para o português, p. 3. Disponível em <www.sternreview.org $>$.

9 "O petróleo é constituído fundamentalmente por compostos que contêm apenas carbono e hidrogênio, chamados de hidrocarbonetos. A maioria dos combustíveis de uso diário consiste em misturas de hidrocarbonetos derivados do petróleo: gás de cozinha, gasolina, querosene e óleo diesel. A queima desses combustíveis representa, no momento, uma das maiores fontes de energia para a humanidade" (PERUZZO, Tito Miragaia; CANTO, Eduardo Leite, Química na abordagem do cotidiano, São Paulo, Moderna, 1996).

10 Segundo o Atlas One Planet, Many people, o "dióxido de carbono, o gás largamente responsabilizado pela maior parte Aquecimento Global, alcançou níveis recordes na atmosfera. Os níveis do dióxido de carbono elevaram-se 30 por cento dentro os últimos 200 anos em conseqüência das emissões industriais, dos automóveis, e do rápido crescimento das industriais e das queimas de florestas especialmente nos trópicos. Muito deste aumento ocorreu desde 1960". (United Nations Environment Program, 2005, p. 81. Disponível em <http://www.na.unep.net>. Acesso em 20/07/2007). No original: "Carbon dioxide, the gas largely blamed for global warming, has reached record-high levels in the atmosphere (Hanley 2004). Carbon dioxide levels have risen by 30 per cent in the last 200 years as a result of industrial emissions, automobiles, and rapid forest burning, especially in the tropics. Much of this increase has occurred since 1960". A partir da década de 1960 o mundo experimenta uma extraordinária expansão no consumo de energia e de insumos fósseis. Segundo Daniel Yergin (O Petróleo: uma história de ganância, dinheiro e poder. São Paulo: Página Aberta, 1994, p. 562), "no final da década de 60 , a população de todas as nações industrializadas estava gozando de um padrão de vida com o qual jamais poderiam ter sonhado há apenas vinte anos. As pessoas tinham dinheiro para gastar e gastavam na compra de casas, de aparelhos elétricos para equipá-las, de sistemas de aquecimento central para aquecê-las e de sistemas de ar condicionado para refrigerá-las. As famílias compravam um automóvel e 
O uso de combustíveis fósseis e as mudanças no uso da terra possuem relação direta com o exponencial crescimento da população mundial, ainda que parte majoritária desta viva em situação paupérrima. Hoje, metade da população mundial vive em áreas urbanas $^{11}$. De acordo com dados de 2006 do Fundo das Nações Unidas para População, nos próximos 43 anos a população irá crescer em 2.5 bilhões de pessoas, quantia igual à população mundial em 1950, e atingir 9.2 bilhões em 2050. Esse crescimento tende a se concentrar em regiões pobres do mundo, especialmente nas áreas urbanas de países em desenvolvimento ${ }^{12}$.

O importante relatório britânico Stern Review alerta para o risco de as mudanças climáticas provocarem, com o aumento da temperatura média na terra, a diminuição da capacidade dos oceanos e solos estocaram GEE, aumentando ainda mais a concentração destes na atmosfera.

Segundo esse mesmo relatório, as mudanças climáticas diferem de outras externalidades por quatro razões: possuem causas e consequências globais; possuem impactos de longo termo e persistentes; as incertezas e os riscos econômicos são abrangentes; há um serio risco de mudanças irreversíveis e com impactos econômicos substanciais. Daí decorre a relevância de aspectos éticos, de eqüidade inter-geracional, e o fato de que as análises de custo benefício

logo depois um segundo. O número de veículos automotores nos Estados Unidos passou de 45 milhões em 1949 para 119 milhões em 1972. Fora dos Estados Unidos o aumento foi ainda mais monumental, passando de 18, 9 milhões de veículos para 161 milhões. Para produzir os carros, os utensílios e as embalagens, para satisfazer direta ou indiretamente as necessidades e os desejos dos consumidores, as fabricas tinham que manter um intenso ritmo de produção, utilizando-se cada vez mais do óleo como combustível. A nova indústria petroquímica transformou o petróleo e o gás natural em matéria plástica e em grande número de produtos químicos, e em qualquer tipo de aplicação o plástico começou a substituir os materiais tradicionais".

11 State of the world population 2007: unleashing the potential for urban growth. Fundo das Nações Unidas para População (UNFPA), 2007, p. 1. Disponível em <www.unfpa.org >. Acesso em 15/09/2007.

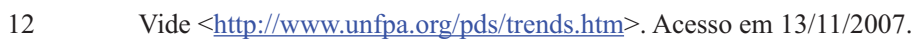

http://www.ucp.br/html/joomlaBR/lexhumana/lexhumana.htm 
tradicionais, baseadas em cálculos abstratos de risco, apenas são úteis como ponto de partida ${ }^{13}$.

\section{Mudanças climáticas, meio ambiente e direitos humanos}

O IPCC relaciona uma série de riscos às mudanças climáticas capazes de impactar de maneira substancial a vida na terra. Dentre os vários exemplos possíveis destacamos o aumento do nível dos oceanos - com a inundação de áreas costeiras densamente ocupadas; o aumento de eventos climáticos extremos como chuvas, ciclones e de áreas sujeitas a processos de desertificação; a perda acelerada de biodiversidade. Esses riscos são em certa medida reforçados por indícios de que as temperaturas já estão mais altas e de que eventos climáticos extremos vêm se tornando mais freqüentes e destrutivos ${ }^{14}$.

O risco climático consiste na possibilidade do aumento considerável da frequência e da intensidade dos eventos antes encarados como 'naturais' e a ocorrência de novos fenômenos (por exemplo, o derretimento das geleiras) com graves consequências sociais e para os quais o mundo não está preparado devido: a fatores biofísicos e biológicos; à dependência das fontes fósseis de energia; ao modelo de desenvolvimento capitalista insustentável e em globalização; ao aumento da população mundial, com a consequente demanda maior por alimentos, energias e produtos dos mais variados; à concentração de partes consideráveis da população em áreas particularmente mais expostas aos eventos climáticos, tais como as costas litorâneas e áreas próximas a leitos de rios, etc.

As mudanças climáticas só viriam a ganhar repercussão graças

13 Stern Review: the economics of climate change. Cambridge, 2006, parte I, p. 10-11; 27.

14 Mudança do Clima 2007: A Base das Ciências Físicas Contribuição do Grupo de Trabalho I ao Quarto Relatório de Avaliação do Painel Intergovernamental sobre Mudança do Clima. Genebra, 2007. 
a sua incorporação à pauta política. Isso acontece principalmente com a criação do Painel Intergovernamental sobre Mudanças Climáticas (IPCC), criado em 1988 pelo Programa das Nações Unidas para o Meio Ambiente (UNEP) e pela Organização Meteorológica Mundial (OMM). Esse Painel tem feito estudos cada vez mais detalhados, abrangentes e dotados de legitimidade perante os Estados nacionais, sendo utilizados como fonte de inspiração para políticas locais, regionais e internacionais. A partir do IPCC começa uma relação entre estudos climáticos e respostas políticas e jurídicas.

Recentemente, contudo essa relação passou a se intensificar de uma maneira não intencional, mas, ao contrário, em razão de eventos climáticos, dentre os quais se destacam: (i) em 2003, uma onda de calor matou cerca de 35 mil pessoas no verão do continente europeu ${ }^{15}$; (ii) em 2005, um furacão de intensidade acima do normal para a época e os padrões da costa leste americana atingiu a cidade de Nova Orleans ${ }^{16}$; (iii) a ilha de Tuvalu, localizada no oceano índico, começa a submergir em razão do aumento do nível das águas oceânicas. Cerca de quatro mil moradores já se mudaram para a Nova Zelândia, chamando a atenção das Nações Unidas para a nova espécie de imigrantes, os refugiados ambientais ${ }^{17}$. Alguns relatórios e estudos já

15 Disponível em $<$ http://agenciact.mct.gov.br> . Acesso em 17/07/2007. Um relatório feito pela organização European Surveillance revisou a estimativa inicial de cerca de 20 mil mortos e constatou que o número pode ter sido até $100 \%$ maior se levados em conta os óbitos ocorridos nos meses de junho e julho do mesmo ano (Eurosurveillance. Vol. 10 Issues 7- July- September 2005. Disponível em $<$ www.eurosurveillance.org $>$. Acesso em 17/07/2007). Segundo matéria publicada no jornal O Globo, em julho de 2007 uma onda de calor teria matado cerca de 500 pessoas somente na Hungria e causado a hospitalização de 19 mil pessoas na Romênia (Quarta-Feira, 25/07/2007, O mundo, p. 33).

16 A força extraordinária do furacão Katrina foi relacionada com o aumento da temperatura média das águas do oceano e o aumento do nível dessas águas, e, desta maneira, ao aquecimento global. Disponível em $<\underline{\text { http: } / / w w w . w o r l d w a t c h . o r g ~}>$. Acesso em 17/07/2007.

17 Jornal O Globo. Ciência. Domingo, 15 de julho de 2007, p. 39. Essa preocupação também é externada pela Agencia para Refugiados da ONU (UNHCR). Segundo artigo na revista da UNHCR, ao abordar a questão dos refugiados ambientais considerou entre as pequenas ilhas mais vulneráveis aos efeitos das mudanças climáticas e que pode submergir com a elevação do mar deixando muito refugiados as Ilhas Marshal, Tuvalu, as Maldivas e as Bahamas. As marés já estão destruindo casas, jardins e fontes 
utilizam a expressão refugiados climáticos e as previsões chegam ao número de 150 milhões em $2050^{18} 19$

Esses efeitos indesejados ligados às mudanças climáticas fazem com que hoje o tema passe a ocupar importantes fóruns políticos internacionais, regionais e nacionais. Um indício deste fato pode ser a imensa repercussão da divulgação dos resultados parciais do Quarto Relatório do IPCC na agenda política internacional no ano de 2007. O aquecimento global também foi alvo de documentários,

de água potável as ilhas Carteret de Papa Novaque pode submergir já em 2015. A evacuação dos dois mil moradores já começou" (Refugees Megazazine, n. 147, Issue 3. Geneva: UNHCR, 2007. Disponível em $<$ www. unhcr.org $>$. Acesso em 17/06/2008).

18 O Relatório da ONG Fiends of The Earth Australia Citzen's Guide for Climate Change Refugees explica mais detalhadamente o caso de Tuvalu. Em no ano de 2000 Governo das Ilhas pediu que Austrália e Nova Zelândia acolhessem os refugiados. Um acordo entre os três países - Pacific Access Category 2007 - estabelece um número de pessoas que podem passar a residir na Nova Zelândia por ano, que é atualmente de 75 pessoas/ano. Essas pessoas devem cumprir com uma série de requisitos exigidos pelo acordo com ter fluência básica em inglês. Já a Austrália negou o 'asilo' aos refugiados (disponível em $<$ www.foe.org.au>. Acesso em 12/08/2007.

19 Nesse sentido merecem destaque as considerações finais feitas em trabalho específico acerca da figura do refugiado ambiental perante o direito internacional e reproduzidas a seguir: "o século XXI apresenta vários desafios para a humanidade e é indubitável afirmar que hodiernamente vivemos numa sociedade de risco com sérios desdobramentos na questão ambiental. Com efeito, há várias situações que demonstram claramente o afirmado acima com um rol alargado de sintomas que apresentam essa realidade: o contínuo desaparecimento de espécies da fauna e da flora; a perda de solos férteis pela erosão e pela desertificação; o aquecimento da atmosfera e as mudanças climáticas; a diminuição da camada de ozônio; a chuva ácida; o acúmulo crescente de lixo e resíduos industriais; o colapso na quantidade e na qualidade da água; o efeito estufa e o aquecimento global. Situações como essas devem despertar posições diferenciadas por parte dos vários atores internacionais: Estados, OIs, ONGs, da sociedade civil, com grandes reflexos para a comunidade jurídica. Nesse sentido, é que não se pode deixar de ressaltar a imperiosa necessidade de reconhecer formalmente a situação jurídica do refugiado ambiental, por não estar prevista nos documentos internacionais e nem tampouco nas legislações dos Estados que regulam a matéria, apesar da realidade fática do conceito demonstrada acima. Além dos casos demonstrados ao longo do artigo (Furacão Katrina e Tsunami), não se pode olvidar que com o aquecimento global e o conseqüente aumento do volume das águas, estão sendo criadas grandes e reais expectativas de que alguns países sejam "condenados à morte", tais como: Ilhas Maldivas, Tuvalu, etc. E os milhões de refugiados ambientais que serão produzidos a partir desses fatos? Diante desse quadro calamitoso que se desenha já no início desse século, a sociedade internacional deve assistir inerte a tudo isso? Obviamente que não. Deve haver o reconhecimento por parte da sociedade internacional do termo e da condição jurídica do 'refugiado ambiental', bem como a devida formalização de seu conceito em tratados internacionais e a conseqüente proteção para àqueles que foram, são ou serão retirados de seus lares por fenômenos impressionantes que estão sendo produzidos pela mãe natureza" (AVZARADEL, Pedro Curvello Saavedra; GUERRA, Sidney. O direito internacional e a figura do refugiado ambiental: reflexões a partir da Ilha de Tuvalu. In: Anais do XVII Congresso Nacional do CONPEDI. Brasília: 2008, p. 2748). 
filmes e shows temáticos e ganhou não somente a primeira página dos jornais ${ }^{20}$, mas também matérias de capa em revistas de circulação nacional.

De acordo com os mais atuais e reconhecidos estudos científicos, os países em desenvolvimento serão os mais afetados pelas mudanças climáticas por três motivos: a temperatura nesses países é, em média, maior do que a dos países desenvolvidos; a economia desses países é mais dependente de atividades agrícolas, extremamente sensíveis às mudanças no clima; esses países dispõem de poucos recursos para se adaptarem ${ }^{21}$. Estudos apontam para a forte probabilidade de o continente africano ser o mais prejudicado nos próximos séculos 22 .

Considerados os argumentos acima expostos, as mudanças climáticas representam um fator capaz de piorar ainda mais as condições de vida de porções da população mundial que já se encontram em situações de extrema miséria, sem conhecer a tutela efetiva de sua dignidade e os demais direitos necessários ao seu pleno desenvolvimento enquanto seres humanos.

\footnotetext{
$20 \quad$ No dia 3 de fevereiro de 2007 o tema ganhou matéria de capa no Jornal O Globo com o título "S.O.S planeta" e do Jornal do Brasil com o título "Apocalipse com data marcada". Nesse dia o Jornal O Globo trouxe 11 matérias sobre o tema (vide Anexo I). Segundo pesquisa feita nos arquivos do Jornal Folha de São Paulo, o número de menções aos assuntos 'aquecimento global', 'efeito estufa' e 'mudanças climáticas' foi de 1.259 contra 459 em 2006 (Rumo a um Novo Consenso pela Sustentabilidade? Os Brasileiros diante das Mudanças Climáticas. Market Analysis, 2007, p. 8). Segundo a pesquisa, 84\% dos brasileiros enxergam as mudanças climáticas como problema muito grave. Esse alto percentual está, ainda segundo a pesquisa, relacionado com o aumento da exposição do tema na mídia (idem, p. 9-10). A pesquisa ouviu 804 pessoas nas oito maiores capitais do país. Disponível em www.marketanalysis.com. br. Acesso em 28/04/2008. A pesquisa foi incorporada à outra internacional feita em moldes parecidos em vários países e compilada pela BBC WORLD SERVICE POLL na pesquisa BBC Climate Survey. Disponível em http://news.bbc.co.uk/. Acesso em 28/04/2007.

21 Stern Review: the economics of climate change. Cambridge, 2006. Parte 1, p. 29. Disponível

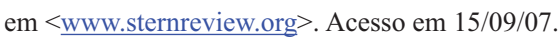

22 O IPCC reconhece que os impactos serão mistos em função das regiões, das trajetórias de desenvolvimento e das estratégias de mitigação adotadas. O IPCC também traz alguns dados específicos por continente. Vide Adaptação e Vulnerabilidade. Contribuição do Grupo de Trabalho II ao Quarto Relatório de Avaliação do Painel Intergovernamental sobre Mudança do Clima. Sumário para políticos. Genebra. 2007. Disponível em < www.mct.gov.br/clima $>$. Acesso em 15/09/2007.
} 
Nesse sentido são as considerações de Foster Brown, Padre René Salizar e Eduardo Cazuza Borges, oportunamente transcritas abaixo:

"o dia 10 de dezembro representou o $60^{\circ}$ aniversário da assinatura da Declaração Universal dos Direitos Humanos. Este documento da Organização das Nações Unidas (ONU) tem servido como uma inspiração para constituições nacionais e convênios internacionais, e ao mesmo tempo, tem mostrado a distância entre as palavras e as ações de países na garantia dos direitos humanos. Em 1948, quando foi assinada a Declaração Universal de Direitos Humanos em Paris, a sombra da Segunda Guerra Mundial afetou as delegações. A guerra, um dos piores violadores de direitos, continua espalhada com 25 conflitos acontecendo no mundo. Porém, existe um novo violador de direitos humanos que não foi concebido sessenta anos atrás: as mudanças climáticas" ${ }^{23}$.

Hoje existe um verdadeiro abismo entre as discussões técnicocientíficas acerca mudanças climáticas - realizadas com base nas ditas ciências duras (ex: engenharia, física, etc.) - e a discussão dos impactos desse mesmo fenômeno na qualidade digna de vida tutelada pelos

23 Direitos humanos e mudanças climáticas. In: Jornal A Gazeta de Rio Branco de 10/12/2008. Disponível em <www.ecodebate.com.br/tag/direitos-humanos $>$. Acesso em 29/06/2009. 
direitos fundamentais ${ }^{24}$ como o direito à saúde, ao meio ambiente equilibrado, o direito à moradia e até mesmo o direito à vida ${ }^{25}$.

No que se refere ao meio ambiente, nunca é demais lembrar que, nos termos da Declaração de Estocolmo "o homem é ao mesmo tempo obra e construtor do meio ambiente que o cerca, o qual lhe dá sustento material e the oferece oportunidade para desenvolver-se intelectual, moral, social e espiritualmente (...) os dois aspectos do meio ambiente humano, o natural e o artificial, são essenciais para o bem-estar do homem e para o gozo dos direitos humanos fundamentais, inclusive o direito à vida mesma" 26 .

De acordo com o princípio inaugural do aludido documento, "o homem tem o direito fundamental à liberdade, à igualdade e ao desfrute de condições de vida adequadas em um meio ambiente de qualidade tal que the permita levar uma vida digna e gozar de bem-estar, tendo a solene obrigação de proteger e melhorar o meio ambiente para as gerações presentes e futuras".

Não obstante, esse abismo já começa a ser percebido no meio jurídico. Um feliz exemplo é a Resolução do Conselho CentroAmericano de Procuradores de Direitos Humanos sobre Mudanças Climáticas, editada na reunião ocorrida em maio de 2008 em El Salvador, segundo a qual "los gobiernos de la región centroamericana en las negociaciones multilaterales, deben incorporar la perspectiva de los derechos humanos y los principios de justicia y equidad ambiental con el objetivo de alcanzar el pleno desarrollo de la persona humana y los pueblos" 27.

$24 \quad$ Em se tratando dos direitos fundamentais, esclarece José Afonso da Silva que "no qualificativo fundamentais acha-se indicação de que se tratam de situações jurídicas sem as quais a pessoa humana não se realiza, não convive e, às vezes, nem mesmo sobrevive: fundamentais do homem no sentido de que a todos, por igual, devem ser, não apenas formalmente reconhecidos, mas concreta e materialmente efetivados. Do homem, não como o macho da espécie, mas no sentido de pessoa humana" (SILVA, José Afonso da. Direito Constitucional Positivo. São Paulo: Malheiros, 2000, p.720).

25 Nesse sentido é o relatório Mudanças Climáticas e Direitos Humanos, editado pelo Conselho Internacional de Políticas sobre Direitos Humanos (Geneva: 2008).

26 Declaração de Estocolmo sobre Meio Ambiente Humano, preâmbulo.

27 Resolução do Conselho Centro-Americano de Procuradores de Direitos Humanos sobre Mudanças Climáticas. El Salvador: 2008. Disponível em $<$ http://www.defensoriadelpueblo.gob.pa $>$.

http://www.ucp.br/html/joomlaBR/lexhumana/lexhumana.htm 
Assim, é preciso que a questão das mudanças climáticas seja cada vez mais analisada sob o ponto de vista das ciências sociais com o intuito de avaliar possíveis impactos sobre os direitos humanos, especialmente naquelas regiões que serão provavelmente as mais afetadas. Ainda, a própria discussão pela comunidade internacional de novos acordos deve enfrentar essas questões com o objetivo de buscar as soluções possíveis.

\section{Respostas oferecidas pela comunidade internacional}

A emergência das mudanças climáticas enquanto nova problemática global expôs uma série de deficiências institucionais e sociais de todo o mundo. Tal como entendem os cientistas do IPCC, essas mudanças seriam o resultado de anos de utilização de combustíveis fósseis, destruição de florestas e coberturas vegetais em todo o mundo, entre outras causas.

Em suma, a questão estaria ligada aos modos de produção e consumo capitalistas em pleno e acelerado processo de expansão global e sem significativas preocupações ambientais nos últimos três séculos. Nem o mercado e nem os aparelhos estatais isoladamente se mostram capazes de responder de maneira adequada ao problema em sua complexidade. Da necessidade de cooperação internacional nascem acordos e uma série de instituições e mercados, voluntários ou legalmente instituídos.

Em razão da necessidade de se responder à questão das mudanças climáticas de maneira eficaz e num espaço curto de tempo, diversas instituições começaram a ser criadas em todo o mundo, seja no âmbito internacional sob o amparo das Nações Unidas, seja em ordenamentos estatais e regionais.

Acesso em 29.06.2009.

http://www.ucp.br/html/joomlaBR/lexhumanallexhumana.htm 
O Direito pode ser considerado apenas como um conjunto de normas emanadas de uma determinada sociedade organizada, cuja legitimidade é presumida de acordo com identidade de quem as edita, o que em geral se classifica como uma visão positivista. Pode também ser visto com desdobramento normativo de princípios superiores de origem metafísica (cosmológica, religiosa, teológica ou até antropológica) que conferem legitimidade às normas editadas. Entretanto, as visões acima se mostram isoladamente insuficientes na descrição do que seja o Direito, que pode ainda ser visto como instrumento de dominação, libertação, controle social, entre outros ${ }^{28}$.

O Direito Ambiental - conceituado aqui como ramo da ciência jurídica dotado de autonomia e unidade formadas a partir de um conjunto próprio de objetos, regras e princípios - surge na década de 1970 a partir da necessidade de o Estado passar a garantir a perpetuação de processos ecológicos, a preservação e a conservação de bens diversos da natureza.

François OST explica a emergência do Direito do ambiente a partir das mudanças de papel do Estado e da construção da questão econômica de forma problemática e crítica. Nesse contexto, o Estado pretende garantir uma proteção ao ambiente não obtida de maneira satisfatoriamente até aquele momento pela propriedade e pelo mercado ${ }^{29}$.

Em idêntico diapasão, Alexandre Kiss diz que: "em conseqüência aos marcos ocorridos na década de 1960, a Sociedade Internacional consagraria na década seguinte a tutela do meio ambiente enquanto universalidade de bens de natureza difusa. Se antes havia leis que protegessem determinados recursos, a partir da década de 1970, o Direito passou a tutelar todo e qualquer

28 FILHO, Roberto Lyra. O que é o Direito? Brasília: Ed. Brasiliense, 1982, p. 33-66.

29 A Natureza à Margem da Lei: A Ecologia à prova do Direito. Lisboa: Instituto Piaget, 1995, p. 119.

http://www.ucp.br/html/joomlaBR/lexhumana/lexhumana.htm 
elemento, seja natural, artificial ou cultural, necessário à sadia qualidade de vidas das presentes e futuras gerações" ${ }^{\prime \prime}$.

Além de limitar em certos aspectos as atividades humanas, o Direito Ambiental traz instrumentos para gerir os riscos da intervenção dos seres humanos sobre o seu entorno. Ou seja, as incapacidades na gestão de riscos bem como o surgimento de ameaças incluem certa incapacidade do paradigma jurídico.

A proteção do ambiente pelo Direito surge de maneira global e sistemática nas conferências de Estocolmo (1972) e do Rio de Janeiro (1992) com a edição de declarações de princípios gerais que influenciaram a expedição de uma série de normas nacionais e internacionais, com destaque para a Convenção Quadro das Nações Unidas sobre Mudanças Climáticas (CQMC) e o Protocolo de Quioto (PQ).

A criação do IPCC e a repercussão dos estudos climáticos a partir de 1990 mostram o início da relação entre ciência climática e sua reflexão política e jurídica. Dentre os frutos colhidos dessa relação podemos destacar a Convenção Quadro sobre Mudanças Climáticas de Nova York (CQNMC) e o Protocolo de Quioto.

A CQNMC, em vigor desde 1994, é uma norma de direito internacional de caráter geral (convenção guarda-chuva) que institui um micro sistema normativo entre os Estados participantes, possibilitando que os mesmos editem normas de caráter específico. O objetivo da Convenção é mitigação das mudanças climáticas e sua estabilização de forma a permitir a adaptação dos ecossistemas, a segurança alimentar e o desenvolvimento (CQMC, artigo $2^{\circ}$ ).

Já o Protocolo de Quioto é uma norma de direito internacional de caráter específico, aprovada na $3^{\text {a }}$ Conferencia das Partes da

$30 \quad$ Direito Internacional do Ambiente, versão traduzida por Maria Gabriela de Bragança. Lisboa: Centro de Estudos Jurídicos, 1996, p. 5.

http://www.ucp.br/html/joomlaBR/lexhumana/lexhumana.htm 
CQMC em 1997 e em vigor desde fevereiro de 2005. O acordo prevê vários períodos de compromisso nos quais os países participantes devem reduzir suas emissões de GEE. No primeiro período, que compreende os anos de 2008 a 2012, os países signatários e considerados desenvolvidos (listados no Anexo I da norma), deverão cumprir a meta de redução agregada de 5\% das emissões em relação ao ano de 1990.

Atualmente existem indícios de que: (i) as mudanças climáticas já nos afetam e representam uma ameaça para a humanidade; (ii) as metas estabelecidas pelo Protocolo de Quioto são insuficientes frente às reduções de emissões de GEE necessárias para permitir uma adaptação adequada às mudanças climáticas ${ }^{31}$; (iii) as emissões globais de GEE continuam a crescer, mesmo com a entrada em vigor do Protocolo ${ }^{32}$.

Diante deste quadro, a sociedade internacional negocia atualmente um novo acordo com metas e compromissos também para os países em desenvolvimento. No plano interno, o Brasil recentemente editou a Política Nacional de Mudanças Climáticas ${ }^{33}$.

Embora haja um movimento na direção de um novo acordo,

Stern Review: the economics of climate change. Cambridge, 2006. Disponível em www.
sternreview.org, acesso em $15 / 09 / 07$. Segundo relatório, a concentração atual de C02 na atmosfera já
está em 430ppm e deve chegar facilmente a 550ppm até 2050, importando numa grande probabilidade
de um aumento na temperatura média de mais de $2^{\circ} \mathrm{C}$. Qualquer aumento acima desse poderá gerar sérias
e catastróficas mudanças no clima. Ainda segundo o mesmo relatório: "a estabilização da concentração
de $\mathrm{CO}_{2}$ e em ou abaixo de $550 \mathrm{ppm}$ exigiria que as emissões globais atingissem seu nível máximo nos
próximos 10 a 20 anos e que depois baixassem à taxa anual de, no mínimo, 1 a $3 \%$.. É necessário que
até 2050 as emissões globais fiquem cerca de $25 \%$ abaixo dos níveis atuais. Estas reduções terão de ser
feitas dentro do contexto de uma economia mundial que, em 2050, poderá ser 3 a 4 vezes maior do que a
de hoje - portanto, as emissões por unidade de PIB deveriam ficar em apenas um quarto dos níveis atuais
até 2050 ".
$32 \quad$ Segundo matéria publicada no portal do Ministério da Ciência e Tecnologia (http://agenciact.
mct.gov.br, acesso em 20 de agosto de 2006$)$ um estudo feito Banco Mundial, entre 1992 e 2002 aponta
que as emissões de dióxido de carbono (CO2) aumentaram em $15 \%$ nesse período e que China e Índia
aumentaram suas emissões em $33 \%$ e $57 \%$, respectivamente. $33 \quad$ Lei 12.187 de 29 de dezembro de 2009.

http://www.ucp.br/htmlljoomlaBR/lexhumanallexhumana.htm 
chamado Pós-Quioto, cabe deixar claro que isto é não apenas desnecessário como infrutífero. Primeiramente porque a edição do Protocolo de Quioto resultou de intensas e longas discussões que não precisam ser totalmente refeitas. A base do acordo - precaução dos riscos climáticos drásticos e a adoção de políticas públicas pautadas nas responsabilidades comuns porém diferenciadas - ainda é válida. Refazer esse processo é desnecessário e requer um tempo do qual não mais se dispõe. Toda a estrutura do Protocolo de Quioto (Conferencia das Partes; Corpos Subsidiários; Comitês de Cumprimento e Secretariado Executivo) está em funcionamento e necessita ser fortalecida.

O segundo e mais forte argumento é que, ao contrário do que se diz, o Protocolo de Quioto não expira em 2012! O período de 2008 a 2012 é tão somente o primeiro (artigo $3^{\circ}$, item 7). Os compromissos subseqüentes para as partes do Anexo I devem ser estabelecidos por emendas aos Anexos A da CQMC ${ }^{34}$ e B do Protocolo (artigo 3º, item 9).

A implementação do acordo está sob permanente revisão pela Conferencia das Partes do Protocolo com vistas a sua eficácia (artigo 13, item 4). Por fim, tanto o texto do Protocolo quanto seus anexos I (com países considerados desenvolvidos) e B (com metas de redução de GEE atribuídas) podem ser emendados com adesão mínima de $3 / 4$ dos signatários a emenda, que deve ser proposta e comunicada pelo Secretariado ao menos 6 meses antes da Conferencia Anual das Partes (artigos 20 e 21). Para que se inclua uma parte no Anexo B (cogita-se estabelecer metas para os Estados Unidos, Brasil, China e Índia) é necessário o consentimento da parte a ser incluída.

O ponto central da questão é o envolvimento de "atores"

34 Obs: Já houve, inclusive, revisão deste anexo, pela Decisão 4 da COP 3. Foram incluídos Croácia, da República Tcheca, de Liechtenstein, de Mônaco, da Eslováquia e da Eslovênia. 
chaves da sociedade internacional e a adoção de políticas mais rígidas e ambiciosas no que concerne à redução das emissões de GEE e à adaptação aos efeitos inevitáveis, fazendo-se mister neste sentido a aplicação de forma substancial do princípio da precaução. Vale trazer à baila as conclusões extraídas em estudo anterior.

"Ao que tudo indica, vivemos hoje num planeta já em processo de mudança no clima. Diante da incerteza científica acerca das conseqüências exatas das mudanças climáticas, mas ante um consenso em instancias científicas chaves de sua ocorrência, faz-se mister aplicar o princípio da precaução de maneira consistente. Para tanto os Estados devem adotar políticas públicas que por meio de instrumentos normativos, econômicos e de mercados nacionais de emissões façam com que os poluidores da atmosfera internalizem os custos desta precaução e da adaptação aos efeitos das mudanças climáticas" ${ }^{\prime 35}$.

As maiores dificuldades para a continuidade do Protocolo de Quioto são políticas e não jurídicas. A resistência à adoção de políticas públicas consistentes e à inclusão de atores chaves no quadro de países com metas de redução de emissões não será superada com a substituição do Protocolo de Quioto por qualquer outro tratado, por melhor que seja.

35 AVZARADEL, Pedro Curvello Saavedra. Princípios do Direito Ambiental e Mudanças Climáticas: uma abordagem a partir da teoria da sociedade de risco. In: Anais do II Simpósio Dano Ambiental na Sociedade de Risco. Florianópolis: 2007, p. 708.

http://www.ucp.br/html/joomlaBR/lexhumana/lexhumana.htm 


\section{Conclusões}

A partir do exposto, pode-se concluir que o fenômeno das mudanças climáticas representa um risco sério para o agravamento dos problemas ligados aos direitos humanos. Representa um fator de risco para questões como o acesso ao meio ambiente equilibrado, o direito à moradia e até mesmo o direito à vida, intimamente ligadas ao pleno desenvolvimento dos seres humanos.

Levando em conta magnitude e a complexidade deste fenômeno, a comunidade internacional começou um processo de cooperação e diálogo com o objetivo de encontrar soluções conjuntas, dentre as quais se destacam a Convenção Quadro e o Protocolo de Quioto.

No presente momento, a sociedade internacional debate a celebração de um acordo internacional que venha a "substituir" o já existente Protocolo de Quioto. Não obstante, descartar todo o acúmulo representado por este protocolo e simplesmente assinar outro tratado, além de desnecessário, é pouco eficiente, considerandose a urgência do enfrentamento das questões climáticas e os riscos que estas representam para a efetiva tutela dos direitos humanos em todo o mundo.

\section{Referências Bibliográficas}

AVZARADEL, Pedro Curvello Saavedra. Princípios do Direito Ambiental e Mudanças Climáticas: uma abordagem a partir da teoria da sociedade de risco. In: Anais do II Simpósio Dano Ambiental na Sociedade de Risco. Florianópolis: 2007. 
AVZARADEL, Pedro Curvello Saavedra; GUERRA, Sidney. O direito internacional e a figura do refugiado ambiental: reflexões a partir da Ilha de Tuvalu. In: Anais do XVII Congresso Nacional do CONPEDI. Brasília: 2008, p. 2738 - 2752.

BORGES, Eduardo Cazuza; BROWN, Foster; SALIZAR, Padre René. Direitos humanos e mudanças climáticas. In: Jornal A Gazeta de Rio Branco de 10/12/2008. Disponível em <wwww.ecodebate.com.br/tag/ direitos-humanos >. Acesso em 29/06/2009.

BRACK, Duncan; GRUBB, Michael; VROLIJK, Christian. The Kyoto Protocol: Guide And Assessment. London: Royal Institute of International Affairs, 1999.

CONSELHO INTERNACIONAL DE POLÍTICA SOBRE DIREITOS HUMANOS. Mudanças Climáticas e Direitos Humanos. Geneva: 2008.

FILHO, Roberto Lyra. O que é o Direito? Brasília: Ed. Brasiliense, 1982.

FUNDO DAS NAÇÕES UNIDAS PARA POPULAÇÃO (UNFPA). State of the world population 2007: unleashing the potential for urban growth. 2007. Disponível em <www.unfpa.org>. Acesso em 15/09/2007.

GOVERNO DO REINO UNIDO. Stern Review: the economics of climate change. Cambridge, 2006. Disponível em < $\underline{w w w . s t e r n r e v i e w}$. org>. Acesso em 15/09/07.

GUERRA, Sidney César Silva. Direito Internacional Público. Rio de Janeiro: Freitas Bastos, 2004.

http://www.ucp.br/html/joomlaBR/lexhumana/lexhumana.htm 
. Direito Internacional Ambiental. Rio de Janeiro: Maria Augusto Delgado Livraria Distribuidora e Editora, 2006.

KISS, Alexandre. Direito Internacional do Ambiente, versão traduzida por Maria Gabriela de Bragança. Lisboa: Centro de Estudos Jurídicos, 1996.

ORGANIZAÇÃO DAS NAÇÕES UNIDAS. Declaração de Estocolmo sobre Meio Ambiente. Estocolmo, 1972. Disponível em < $\underline{w w w}$. un.org >. Acesso em 15/09/2007.

Declaração do Rio sobre

Meio Ambiente e Desenvolvimento. Rio de Janeiro, 1992. Disponível em < www.un.org>. Acesso em 15/09/2007.

OST, François. A Natureza à Margem da Lei: A Ecologia à prova do Direito. Lisboa: Instituto Piaget, 1995.

PAINEL INTERGOVERNAMENTAL DE MUDANÇAS CLIMÁTICAS (IPCC). IPCC Special Report on Land Use, Land Use Change and Forestry, 2000. Disponível em <www.ipcc.ch>. Acesso em 23/06/07.

Mudança

do Clima 2007: A Base das Ciências Físicas Contribuição do Grupo de Trabalho I ao Quarto Relatório de Avaliação do Painel Intergovernamental sobre Mudança do Clima. Genebra, 2007. Disponível em <www.mct.gov.br/clima $>$. Sumário para políticos. Acesso em 15/09/07. 


\section{Mudança}

do Clima 2007: Adaptação e Vulnerabilidade. Contribuição do Grupo de Trabalho II ao Quarto Relatório de Avaliação do Painel Intergovernamental sobre Mudança do Clima. Sumário para políticos. Genebra. 2007. Disponível em <www.mct.gov.br/clima $>$. Acesso em 15/09/2007.

PERUZZO, Tito Miragaia; CANTO, Eduardo Leite, Química na abordagem do cotidiano, São Paulo, Moderna, 1996.

PROGRAMA DAS NAÇÕES UNIDAS PARA MEIO AMBIENTE (UNEP). Atlas One Planet, Many people, 2005. Disponível em < $\underline{w w w}$. unep.org >. Acesso em 15/09/2007.

PROGRAMA DAS NAÇÕES UNIDAS PARA REFUGIADOS (UNHCR). Refugees Megazazine, N. 147, Issue 3. Geneva: UNHCR, 2007. Disponível em <www.unhcr.org>. Acesso em 17/06/2008.

SILVA, José Afonso da. Direito Constitucional Positivo. São Paulo: Malheiros, 2000.

YERGIN, Daniel. O Petróleo: uma história de ganância, dinheiro e poder. São Paulo: Página Aberta, 1994. 